http://jmscr.igmpublication.org/home/ ISSN (e)-2347-176x ISSN (p) 2455-0450 crossref DOI: https://dx.doi.org/10.18535/jmscr/v8i2.74

\title{
Influence of Blood Collection Methods on Some Analytes; Potassium and Sodium
}

Authors

\section{Dr Frederick Igila Allison ${ }^{1}$, Bamigbowu Emmanuel Olugbenga ${ }^{1}$, Dr Shittu Lukman ${ }^{2}$}

${ }^{1}$ Faculty of Basic Health Sciences, Department of Chemical Pathology, University of Port-Harcourt, Rivers State, Nigeria

${ }^{2}$ University of Port Harcourt Teaching Hospital, Department of Chemical Pathology, Rivers State, Nigeria Corresponding Author

Dr Allison Frederick Igila

Faculty of Basic Health Sciences, University of Port-Harcourt, Rivers State, Nigeria

\section{Background}

Haemolysis is a common occurrence in blood sample collection ${ }^{1}$, the severity of which may compromise the quality of laboratory test results. Many factors may cause haemolysis of blood samples and these include method of blood collection, method of emptying into container, blood anticoagulant ratio, transportation methods and blood sample storage among others. Methods of blood collection are very vital to ensuring quality results from the laboratory, especially for intracellular analytes ${ }^{2}$. Most times, the method of sample collection is overlooked to the detriment of quality of blood sample and patient care. This is important as haemolysis releases highly concentrated intracellular analytes into the plasma: analytes like potassium, magnesium, phosphate, lactate dehydrogenase among others, ${ }^{3}$ have been found to increase in plasma due to haemolysed. Most times in our laboratories and hospitals the visual assessment of the degree of haemolysis is the criteria used to reject haemolysed blood sample. Studies have shown that about $70 \%$ of blood sample rejection in our laboratories is due to haemolysis ${ }^{4,}$ and this to a reasonable extent depends on the degree of haemolysis which determines the level of effect of these intracellular substances released into plasma ${ }^{5}$.

In our environment, syringes and needle and occasionally vercutiner is used for blood sample collection. In some laboratories and hospitals in this region, the vercutiner is mostly used but still occasionally run out of stock and so syringes and needle are still used occasionally for blood sample collection. These syringes come in different volumes and needle sizes and most commonly used are the $2 \mathrm{ml}, 5 \mathrm{ml}, 10 \mathrm{ml}$ and $20 \mathrm{ml}$ for syringes and either the $21 \mathrm{G}$ or the $23 \mathrm{G}$ size for needle. The size of the needle, speed of draw and speed of emptying collected blood into a container all have different degrees of haemolytic effects on collected samples ${ }^{5}$ Those who use syringes erroneously either squeeze blood through the needles into containers (needle samples) or remove the needle from the syringe before emptying blood sample collected into containers (syringe sample). The vercutiner is specifically 
designed for blood collection and so blood is directly collected into the containers at an automated controlled speed of draw. Sometimes on the same patient, blood samples may be collected using these different methods at different times for the same type of test (Repeat test). These methods could cause different degree of haemolysis which may affect the accuracy of these intracellular analyte and even patient care.

Since all these methods may cause haemolysis to various degrees, this study was therefore designed to investigate the effect these blood sample collection methods have on the accuracy (value) of certain analytes such as potassium and sodium that are analysed on a daily basis in our laboratories.

\section{Subjects and Methods}

A total number of 30 apparently healthy undergraduate students, ages between 20 to 30 years who were not sicklers or without any form of blood disorders and were not on any drugs that is known to affect blood sodium and potassium concentration who volunteered by signing the consent forms were recruited for this study. For each subject, $2 \mathrm{ml}$ of blood was collected with a vercutiner into a lithium heparin anticoagulant container and labelled 'vercutiner sample'. Then, with a $5 \mathrm{ml} 21 \mathrm{G}$ syringe and needle, $4 \mathrm{ml}$ of blood was gently drawn into the syringe. With the needle in situ, $2 \mathrm{ml}$ of same blood is gently emptied into another lithium heparin container and labelled 'needle sample'. The needle is then removed from the syringe and the remaining $2 \mathrm{ml}$ of blood in the syringe is emptied into the third lithium heparin anticoagulant container and labelled 'syringe sample'. That is, for each subject, there were three different lithium heparin samples. These samples were left to stand at room temperature for about an hour and the plasma from each sample was carefully separated into a plain bottle and labelled as vercutiner, needle and syringe samples accordingly. The samples were not centrifuged to eliminate any form of extra haemolysis due to the force of centrifugation ${ }^{6}$.
This was analysed almost immediately in duplicates for sodium and potassium using the ion selective electrode (ISE) by Landwind and the average results taken.

This process was done for all thirty selected subjects and the results grouped under the sample types that is vercutiner, needle and syringe samples. This results of each group is added and their mean calculated and the data analysed using SPSS version 25 (IBM, USA). The differences in the means of the groups were compared using ANOVA.

\section{Results}

The results of the different samples analysed from 30 undergraduate students were analysed as shown in table 1 . About 19 of the students were females and 11 males. The youngest student was 16 years and the oldest was 25 years giving a mean age was 19.93 years.

The lowest potassium values for the three different samples collected by different methods were $3.3,3.3$, and $3.4 \mathrm{mmol} / 1$ for samples collected through the syringe method, the needle method and the vercutiner method respectively. The highest potassium value was $6.9 \mathrm{mmol} / 1$ for the syringe sample, $7.1 \mathrm{mmol} / 1$ for the needle sample and 7.1 for the vercutiner sample. The mean values for each of the three collection methods were 4.587, 4.697 and 4.570 respectively for syringe, needle and vercutiner samples (Table 1). A comparison of their means was not statistically significant. (Table 2).

For the sodium analytes, the lowest value for the syringe sample was $128 \mathrm{mmol} / 1$ and $129 \mathrm{mmol} / \mathrm{l}$ for the needle sample, while the vercutiner sample has a lowest sodium value of $129 \mathrm{mmol} / 1$. The highest sodium value was $150 \mathrm{mmol} / \mathrm{l}$ for all the samples types collected by the different methods (vercutiner, needle and syringe samples). The mean sodium values for the different samples were $141.2 \mathrm{mmol} / 1,141.0 \mathrm{mmol} / \mathrm{l}$ and $140.6 \mathrm{mmol} / 1$ for the syringe, needle and vercutiner samples respectively. 
Table 1: Potassium and Sodium Results

\begin{tabular}{|l|c|c|c|}
\hline Sodium & $\mathbf{S}$ & $\mathbf{N}$ & $\mathbf{V}$ \\
\hline Minimum & 128.0 & 129.0 & 129.0 \\
\hline Maximum & 150.0 & 150.0 & 150.0 \\
\hline Mean & 141.2 & 141.0 & 140.6 \\
\hline Std. Deviation & 7.495 & 6.944 & 6.620 \\
\hline Std. Error of Mean & 2.370 & 2.196 & 2.093 \\
\hline Potassium & $\mathbf{S}$ & $\mathbf{N}$ & $\mathbf{V}$ \\
\hline Minimum & 3.300 & 3.300 & 3.400 \\
\hline Maximum & 6.900 & 7.100 & 7.100 \\
\hline Mean & 4.587 & 4.692 & 4.570 \\
\hline Std. Deviation & 0.7817 & 0.9035 & 0.9097 \\
\hline Std error of mean & 0.1748 & 0.2020 & 0.2034 \\
\hline
\end{tabular}

Table 2: Multiple Comparisons of Potassium and Sodium Mean

\begin{tabular}{|l|c|c|}
\hline POTASSIUM & P Value & Significance \\
\hline S vs. N & 0.7031 & Not significant \\
\hline S vs. V & 0.9522 & Not significant \\
\hline N vs. V & 0.6593 & Not significant \\
\hline
\end{tabular}

\begin{tabular}{|l|c|c|}
\hline SODIUM & P Value & Significance \\
\hline S vs. N & 0.9497 & Not significant \\
\hline S vs. V & 0.8501 & Not significant \\
\hline N vs. V & 0.8997 & Not significant \\
\hline
\end{tabular}

\section{Discussion}

Blood sample collection method is believed to affect the quality of sample as these collection methods are believed to cause certain level of haemolysis $^{7}$. These samples were therefore analysed for potassium and sodium to see the effect of haemolysis on each method of collection. Potassium concentration being higher intracellularly ${ }^{8}$ is believed to increase plasma potassium concentration when blood cells lyse $^{8}$. The variation of plasma potassium concentration can be directly proportional to degree of haemolysis.

The lowest potassium values were $3.3 \mathrm{mmol} / \mathrm{l}$, $3.3 \mathrm{mmol} / 1$ and $3.4 \mathrm{mmol} / \mathrm{l}$ for needle, syringe and vercutiner samples respectively. The needle and the vercutiner had the highest individual potassium value, which was $7.1 \mathrm{mmol} / \mathrm{l}$ for both samples and $6.9 \mathrm{mmol} / \mathrm{l}$ for the syringe sample (Table 1). The mean potassium results for the three sample collection methods showed that the needle sample had the highest potassium mean. This meant the degree of haemolysis was highest for the needle sample and may be due to the fact that blood samples which were emptied into containers with the needle in situ may have further increased the degree of haemolysis thereby increasing the releasing of intracellular potassium from lysed cells into the plasma. This haemolysis is responsible for the differences in the potassium values of the three samples even for the same subject and also responsible the differences in the mean values of the three samples types.

The syringe sample had the lowest potassium mean value in this study and this may be largely due to the controlled draw of blood sample into the syringe ${ }^{9}$, the controlled emptying of blood sample from the syringe into the sample container and due to the fact that the size of the syringe opening is wider that the $21 \mathrm{G}$ needle opening ${ }^{10}$. This is therefore believed to reduce haemolysis when emptying into the container. Though from this study, there were differences in the mean values of potassium concentration of the different samples, the mean vercutiner samples result and the mean syringe samples result were closed and were found not to be statistically and clinically significant. This findings can also be attributed to the fact that the haemolysis caused by these methods of blood sample collections were mild in this study or rather believed to have happened since it was not visually obvious and no test was carried out to prove haemolysis in this study. The differences in the potassium values was therefore used as a proof of haemolysis having measured samples in duplicates.

From the results of this study, the syringe sample may be seen to have a slight advantage over both the needle and the vercutiner samples in terms of the degree of haemolysis. To reduce or eliminate this random error seen with the needle and syringe samples, the use of the vercutiner for sample collection remains the safest and most conducive for sample collection more so since the difference in their means of all the types of samples were not significantly different.

It is important to note that the collection of blood sample by controlled, gentle withdrawal from veins/ arteries into the syringe and controlled 
empting from the syringe into sample container depends on the expertise of the phlebotomist. This therefore means the degree of haemolysis of the needle and syringe samples to an extent depends on the expertise of the phlebotomist ${ }^{11}$. In this study, the effect of the phlebotomist was minimal as the same phlebotomist with the same expertise collected all the sample types. Based on the above fact, potassium values from the needle and syringe samples could vary based on the experience of the phlebotomist.

The lowest sodium value from the three sample types based on their methods of collection were about the same and the highest sodium value of $150 \mathrm{mmol} / \mathrm{l}$ was obtained for all the three sample types. That is, the mean sodium values of the three different sample types were the same irrespective of the method used for sample collection. This may be due to the fact that sodium not being an intracellular analyte, is not released into plasma when blood cells lyse, hence their plasma concentration was not affected by haemolysis (mild haemolysis) $^{12}$. This finding is not in keeping with other studies that noticed a decrease in sodium concentration due to a delusional effect as intracellular fluid is released into plasma in excess of sodium $^{13,14}$ (moderate to severe haemolysis).

Studies have also shown that mild haemolysis has little or no effect on the potassium value ${ }^{15,16}$. Mild in this case may mean haemolysis undetectable by visual inspection, though about $70 \%$ of sample rejection in the laboratory is due to haemolysis ${ }^{1}$. This refers to haemolysis that is obvious on visual inspection. The challenge here is haemolysis that is undetected by visual inspection but can significantly alter intracellular analytes to the detriment of patient care. Therefore in this study the methods adopted for the different sample collections can be said to have different degrees of mild haemolysis.

To arrive at a decision, the advantages of the above methods need be evaluated and weighed against the results of this study. The syringe sample had the lowest potassium mean closely followed by the vercutiner sample (table2) but the vercutiner has an automated controlled speed of draw and therefore is not necessarily affected by the expertise of the phlebotomist. These results observed in this study may therefore be different as the degree of haemolysis of both the syringe and the needle samples depends on the speed of draw of blood into a syringe and the speed of emptying into a container which are both controlled by the expertise of the phlebotomist. In the light of this, and the differences in their mean, the vercutiner should be preferred and its use in our laboratory and hospitals should be encouraged as their level of haemolysis is not predicated on the degree of expertise of the phlebotomist and so can be used by most laboratory staff with little effect on sample quality.

\section{Conclusion}

From this study, methods of sample collection can cause haemolysis as shown by the variations in the results of potassium means. In order to ensure quality samples, the vercutiner method should be encouraged as the degree of haemolysis does not depend on the expertise of the phlebotomist and since the difference in their means and that of the syringe sample was not significantly different. This means quality samples can be collected using the vercutiner method by laboratory staff with different levels of expertise with little effect on quality.

Conflict of Interest: This study has no conflict of interest

Funding: This study is self-funded.

\section{References}

1. Wan Azman WN, Omar J, Koon TS, Tuan Ismail TS. Hemolyzed Specimens: Major Challenge for Identifying and Rejecting Specimens in Clinical Laboratories. Oman Med J. 2019; 34(2):94-98.

2. Bowen RAR, Remaley AT. Interferences from blood collection tube components on clinical chemistry assays. Biochem Med (Zagreb). 2014; 24:31-44 
3. Heins M, Hell W, Withold W. Storage of serum or whole blood samples? Effects of time and temperature on 22 serum analytes. Eur J Clin Chem Clin Biochem. 1995, 33: 231-238.

4. Lippi G, Blanckaert N, Bonini P, Green S, Kitchen S, Palicka V, et al. Haemolysis: an overview of the leading cause of unsuitable specimens in clinical laboratories. Clin Chem Lab Med 2008; 46(6):764-772.

5. Carraro P, Servidio G, Plebani M. Hemolyzed specimens: a reason for rejection or a clinical challenge? Clin Chem 2000. Feb; 46(2):306-307.

6. Mancuso JE, Jayaraman A, Ristenpart WD. Centrifugation-induced release of ATP from red blood cells. PLOS ONE 2018;13(9): e0203270.

7. Heireman L, Van Geel P, Musger L, Heylen E, Uyttenbroeck W, Mahieu B. Causes, consequences and management of sample hemolysis in the clinical laboratory. Clin Biochem 2017; 50(18): 1317-1322.

8. Lippi G, Avanzini P, Cervellin G. Prevention of hemolysis in blood samples collected from intravenous catheters. Clin Biochem2013; 46(7-8):561-4.

9. Asirvatham JR, Moses V, Bjornson L. Errors in potassium measurement: a laboratory perspective for the clinician. $N$ Am J Med Sci. 2013; 5(4):255-259.

10. Moss G, Staunton C. Blood flow, needle size and hemolysis. Examining an old wives' tale, $\mathrm{N}$ Engl J Med 1970;282(17):967.

11. Haseler LJ, Sibbitt RR, Sibbitt WL Jr, Michael AA, Gasparovic CM, Bankhurst AD. Syringe and needle size, syringe type, vacuum generation, and needle control in aspiration procedures. Cardiovasc Intervent Radiol. 2011; 34(3):590-600.
12. Carraro P., Servidio P, Plebani M. Haemolyzed specimens: a reason for rejection or clinical challenge? Clin Chem 2000; 46: 306-307.

13. Guder W. Haemolysis as an influence and interference factor in clinical chemistry. $\mathrm{J}$ Clin Chem Clin Biochem 1986; 24: 125126.

14. Dimeski G. Interference testing. Clin Biochem Rev 2008; 29(8): 43-48.

15. Lippi G, Fontana R, Avanzini P, Sandei F, Ippolito L. Influence of spurious haemolysis on blood gas analysis. Clin Chem Lab Med 2013; 51(8):1651-1654.

16. Koseoglu M, Hur A, Atay A, Cuhadar S. Effects of hemolysis interferences on routine biochemistry parameters. Biochem Med (Zagreb) 2011; 21(1):79-85. 